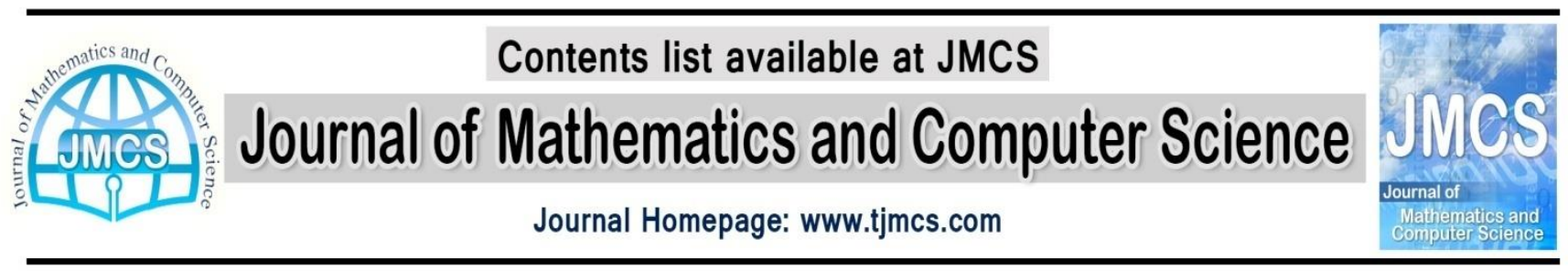

\title{
Linear Integer (LIP) Programing to Optimization and Sizing a Wind/Solar/Battery System for Islanding Purpose
}

\author{
Saeed Reza Nazari Estahbanati* \\ Graduate student, Department of Mechanical Engineering, University of Sistan and Baluchestan, \\ Zahedan, Iran \\ s_r_nazari@yahoo.com \\ S. Masoud Barakati \\ Assistant Professor, Department of Power Electronic Engineering, University of Sistan and Baluchestan, \\ Zahedan, Iran smbaraka@ece.usb.ac.ir \\ Mehri Mehrjoo \\ Assistant Professor, Department of Telecommunication, University of Sistan and Baluchestan, Zahedan, \\ Iran \\ iranmmehrjoo@ece.usb.ac.ir \\ Article history: \\ Received August 2014 \\ Accepted September 2014 \\ Available online October 2014
}

\begin{abstract}
An optimal approach for sizing of stand-alone hybrid distributed generation (DG) power management systems is presented. The methodology is applied to an integrated hybrid system including photovoltaic (PV) panels, wind turbine (WT), and battery (BT). The PV array is operated effectively at the maximum power point tracking. Unit cost of electricity energy (UCEE), as an efficient criterion for the economic assessment and the loss of power supply probability (LPSP), as a suitable criterion for reliable assessment, are used to optimize the system sizing. Typical residential load, solar irradiation, wind speed, and temperature data are collected from the city of Marvdasht, located in Iran, Fars (Latitude: $29^{\circ} 50^{\prime} \mathrm{N}$, Longitude: $52^{\circ} 40^{\prime} \mathrm{E}$ ) to evaluate the proposed technique. A Branch and cut method is employed and coded in MATLAB ${ }^{\circledR}$ environment to optimize configuration of proposed hybrid system. Regarding the stochastic nature of renewable sources and load, the simulation results show the suitable match rate between demand and supply.
\end{abstract}

Keywords: Hybrid renewable wind/PV/battery system, optimization, sizing method, linear integer programing (LIP), LPSP, UCEE. 


\section{Introduction}

Widespread using of fossil fuels to supply the energy needs of industries caused rising in air pollution and temperature. World increasing population and depletion of fossil fuels make the necessity of finding alternative energy resources clear. Wind and solar are clean, accessible and cost-effective energies. In other words wind and solar energy are efficient enough to supply demand on remote area where the electricity costs through the network are high. Hybrid systems are proposed to increase the reliability of the wind or solar system alone. M. Vafaei et al. demonstrated that the hybrid systems are usually more reliable and less costly than systems that use only a single source of energy [1].

Proper design of stand-alone hybrid renewable power systems is a challenging task which included numerous investigations [2]-[6]. Graphical optimization method is used to size the PV/wind hybrid system by considering monthly average meteorological data [8]. An iterative technique (Quasi-Newton) is reported by Ashok to optimize a hybrid system for rural zone by minimizing total life cycle cost and maximizing the power reliability [10]. Technical and economical assessment of hybrid PV/wind system with BT storage for Corsica Island has been performed in [7]. LPSP and Levelized cost of energy (LCE) is considered to achieve a suitable size of components. Power supply failure probability and reliability consideration of hybrid PV/wind/battery systems is investigated in [9].

Using of evolutionary algorithms are considered a lot in recent years [11] - [16]. However, low speed of calculation and unabling to get the exact solution are the basic challenge. Using of classical methods in optimization was decreased by emerging the evolutionary algorithms.

In the present paper, an optimal sizing algorithm is investigated to use in stand-alone hybrid power management DG systems. The proposed hybrid system is consisting of PV and WT, as power supply sources, and a BT, as a storage device. UCEE is used as an economical objective function to minimize the project costs. Reliability is a significant criterion to achieve the proper size which can be checked by LPSP technique. Collected meteorological data of a site located in Iran, Fars, Marvdasht (Latitude: $29^{\circ} 50^{\prime} \mathrm{N}$, Longitude: $52^{\circ} 40^{\prime} \mathrm{E}$ ) is used as a case study. Studies have proved that the proposed LIP technique converges very well and it is feasible for optimally sizing standalone hybrid wind/PV power systems.

\section{Modeling of Stand-Alone Microgrid Power Systems}

In this paper, the hybrid renewable power system consists of three components: WT, PV, and BT. WT and PV panels supply electricity based on the collected local wind and solar radiation data to meet load. The BT is used as a storage system to supply power when WTs and PV panels cannot meet the load. The excess power is also store in the BT.

\subsection{Generated Output Power by the WT}


Usually obtained wind speed data of weather site is not in the height of the turbine hub, so we need to adjust it.

Due to the important influence of the WT height on the energy of the system, it is necessary to consider the wind speed profile for the height of the turbine. In this paper the power laws is utilized. So the wind speed at the height of the hub is presented as below [7]:

$v=v_{r e f}\left(\frac{H}{H_{r \theta f}}\right)^{\alpha}$

Where $v\left(\frac{m}{s}\right)$ is the wind speed at the required hub height $H(m) ; v_{r e f}\left(\frac{m}{s}\right)$ is the wind speed measured at the weather site at the height $H_{r \theta f}(m) . a$ is the ground surface friction coefficient which is considered $\frac{1}{7}$ for the low roughness and open land [17].

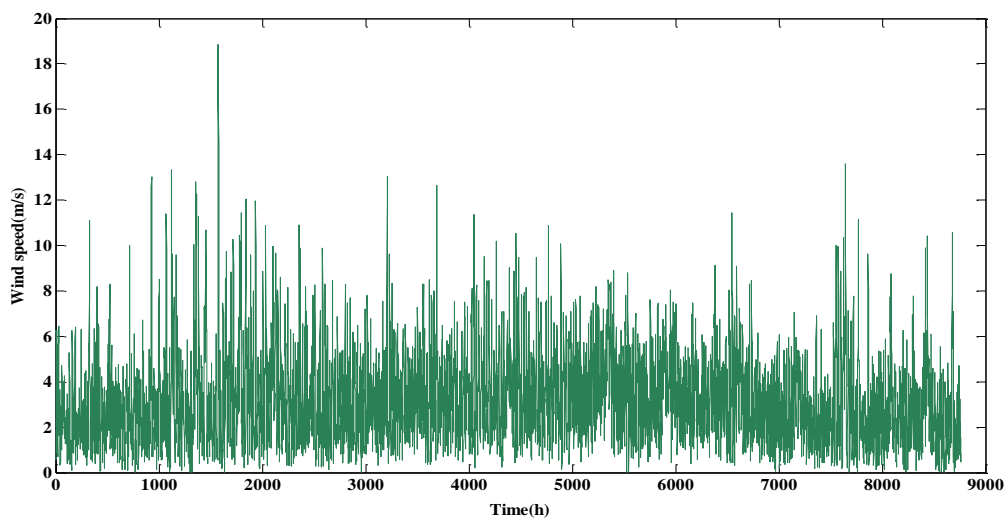

Figure 1. Wind speed profile of Marvdasht weather site for 1 year

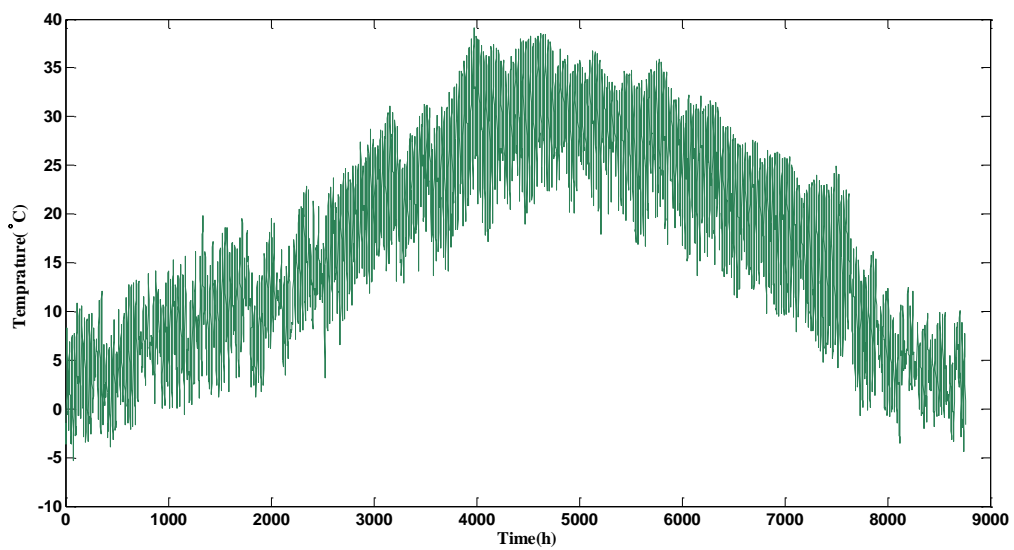

Figure 2. Temperature profile of Marvdasht site for 1 year 
As the wind speed is a probabilistic variable, probability density function (PDF) is a usual way to demonstrate this data. The weibull distribution function estimate wind data by use of two parameters. [6] is expressed common weibull function representation as:

$f(v)=\left(\frac{k}{c}\right) \cdot\left(\frac{v}{c}\right)^{(k-1)} \cdot e^{\left(-\left(\frac{v}{c}\right)^{k}\right)}$

Where $f(v)$ is weibull function, $v\left(\frac{m}{s}\right)$ is improved wind speed, $c$ is scale factor and $k$ is shape factor. Shape of DPF is controlled by shape factor, in this sense, shape factor has a unlike effect on distribution function width. Lower shape factor indicates wider PDF and larger shape factor indicates narrower PDF around mean wind speed value. Scale factor effects on PDF height. As the scale factor is larger, the PDF is taller and the lower value of scale factor makes the shorter PDF.

In accordance weather site of Iran, Fars, Marvdasht (Latitude: $29^{\circ} 50^{\prime} \mathrm{N}$, Longitude: $52^{\circ} 40^{\prime} \mathrm{E}$ ), wind profile is shown in Figure 1 and the ambient temperature profile is illustrated in Figure 2 and wind speed profile, PDF is demonstrated as Figure 3.

The available energy output of WT is estimated by manufactures given power curve and weibull function as illustrated below [18]:

$E_{\text {out }}=n_{\text {days }} \cdot n_{\text {hours }} \cdot P_{c}, f(k, c, v)$

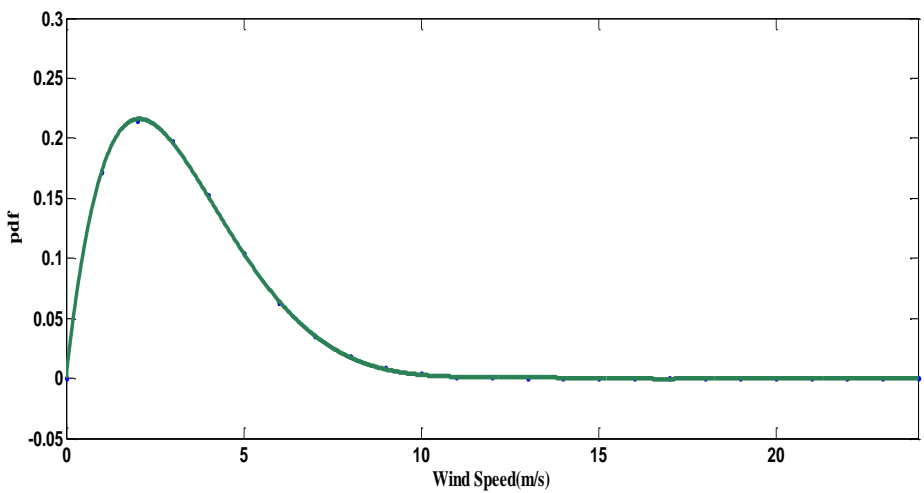

Figure 3. PDF of Marvdasht weather site wind speed profile for 1 year

Where $E_{\text {out }}(K w, h)$ is produced output energy of WT, $P_{c}(K w)$ is output power of selected WT which is given by the manufactures in datasheet, $f(k, c, v)$ is weibull PDF, $n_{d a y s}, n_{k o u r s}$ are the number of days and hours in simulation time period respectively. Small WT "Lakota S, SC" is used in this work and the power curve is demonstrated in Figure 4. 


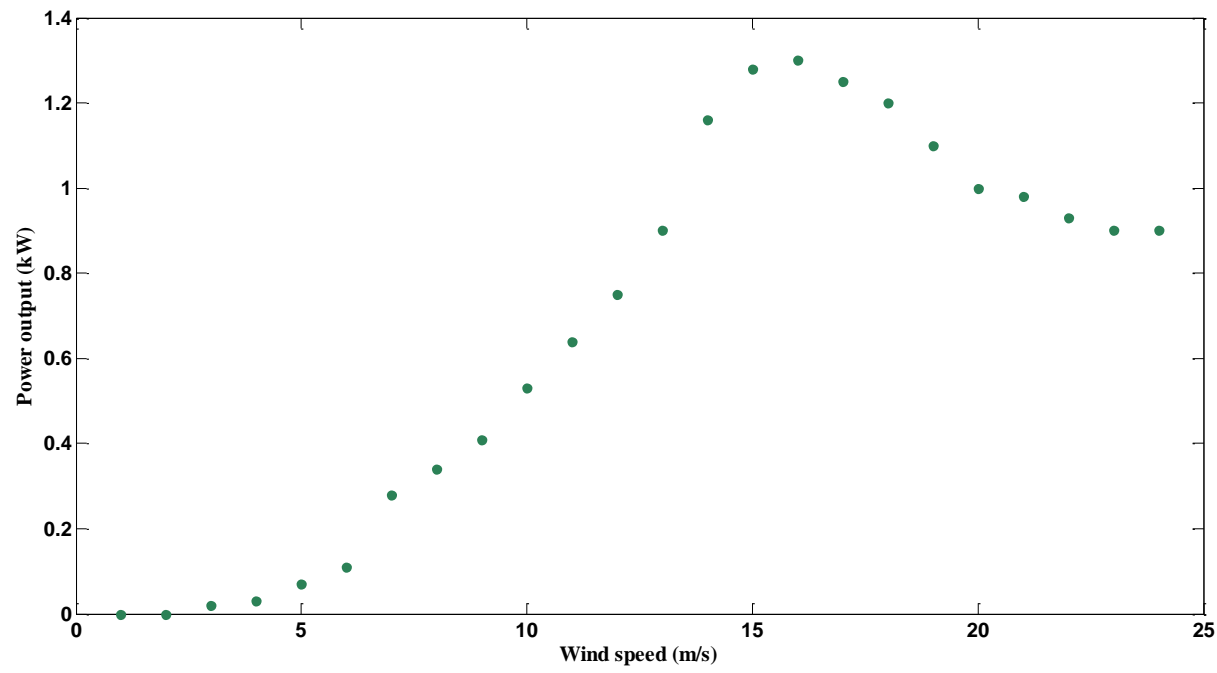

Figure 4. Power curve of "Lakota S, SC"

Yearly energy generated by this type of small WT is illustrated in Figure 5. also.

\subsection{Generated Output Power by the PV Array}

The I-V characteristic of PV array is different by the temperature and the radiation various level of local weather. Likewise the generated power of the PV array depends on the solar radiation and ambient temperature of the site. Maximum power point tracker (MPPT) is a usual controller to adjust the output power of PV array to maximum power at any radiation level. In this investigation the maximum power point tracking is considered in simulation process.

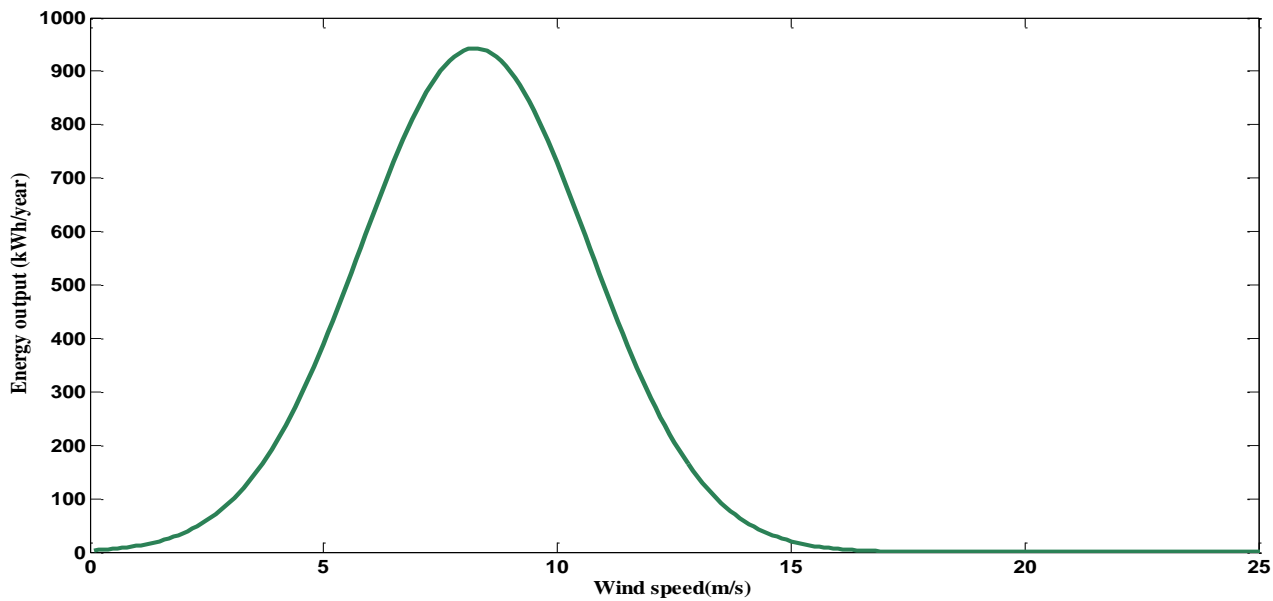

Figure 5. Yearly energy produced by "Lakota S,SC" in accordance to Marvdasht wind speed profile 
The PV array is modeled in accordance of solar radiation profile of Marvdasht weather site which is demonstrated in Figure 6.

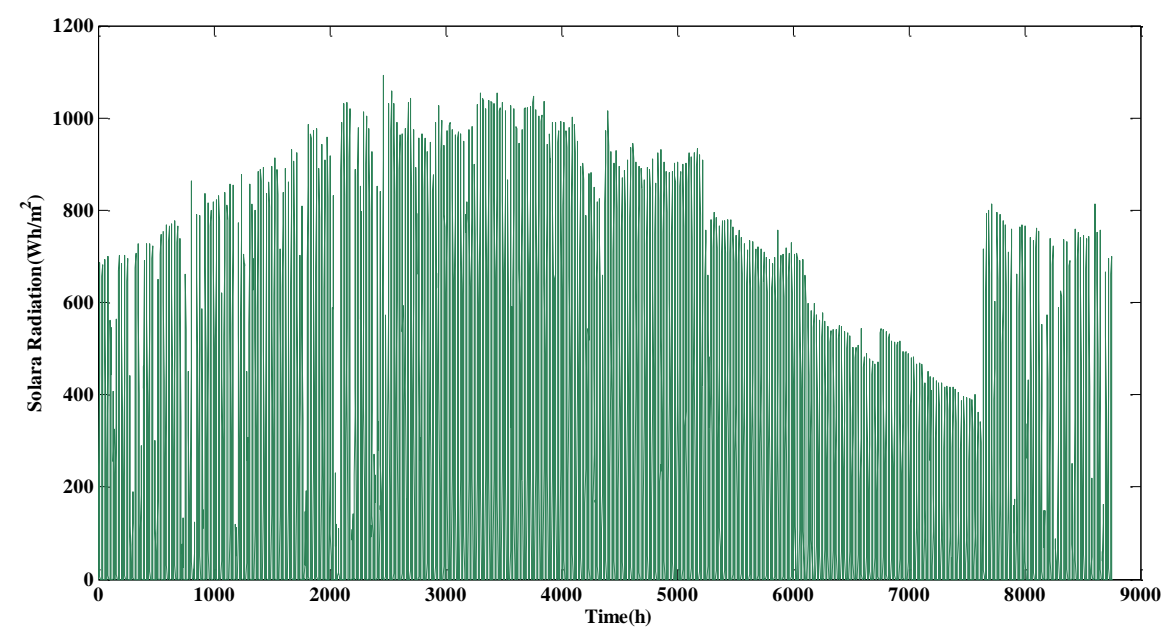

Figure 6. Solar radiation profile of Marvdasht weather site for 1 year.

The output power of a PV array can be obtained of the following equations [19]:

$$
\begin{aligned}
& I(V)=\frac{I_{X}}{1-\theta \times p}\left(-\frac{1}{b}\right) \cdot\left[1-\exp \left(\frac{V}{b V_{x}}-\frac{1}{b}\right)\right] \\
& V_{x}=S \cdot \frac{E_{i}}{E_{i V}} T_{c v} \cdot\left(T-T_{N}\right)+S \cdot V_{\max }-S \cdot\left(V_{\max }-V_{\min }\right) \cdot \exp \left(\frac{E_{i}}{E_{W V}} \cdot \ln \left(\frac{V_{\max }-V_{a c}}{V_{\max }-V_{\min }}\right)\right) \\
& I_{x}=p \cdot \frac{E_{i}}{E_{i N}} \cdot\left[I_{S C}+T_{C i} \cdot\left(T-T_{N}\right)\right] \\
& P(V)=\frac{V \cdot I_{x}}{1-\theta \times p\left(-\frac{1}{b}\right)} \cdot\left[1-\exp \left(\frac{V}{b \cdot V_{x}}-\frac{1}{b}\right)\right]
\end{aligned}
$$

In above equations $P(V)$ in $(w)$ is output power produced by $\mathrm{PV}$ array, $I_{x}$ in $(A)$ is output current of PV array, $V$ in $(v)$ is output voltage of $\mathrm{PV}$ array, $I_{x}$ the short-circuit current and $V_{x}$ is open-circuit voltage at any given $E_{i}$ and $T, I_{s c}$ and $V_{o c}$ the short-circuit current and the open-circuit voltage at $25\left({ }^{\circ} \mathrm{C}\right)$ and 1000 $\left(\mathrm{W} / \mathrm{m}^{2}\right)$, respectively, $V_{\max }$ is the maximum open-circuit voltage at $25\left({ }^{\circ} \mathrm{C}\right)$ and1200 $\left(\mathrm{W} / \mathrm{m}^{2}\right)$ (usually $V_{\max }$ is near to $\left.1.03 V_{o c}\right), V_{\min }$ the minimum open-circuit voltage at $25\left({ }^{\circ} \mathrm{C}\right)$ and $200\left(\mathrm{~W} / \mathrm{m}^{2}\right)$, (usually, $V_{\min }$ is near to $\left.0.85 V_{o c}\right), T$ the solar panel temperature $\left({ }^{\circ} \mathrm{C}\right), E_{i}$ is the effective solar radiation on the cell surface in $\left(\mathrm{W} / \mathrm{m}^{2}\right), T_{w}=25\left({ }^{\circ} \mathrm{C}\right)$ is the standard test condition (STC), $T_{C i}$ the temperature coefficient of $V_{o c}$ in $(V / C)$, the number of series PV panel is $s, p$ is the number of PV panels in parallel and $b$ is the characteristic constant based on $I-V$ curve. The characteristic constant, $b$, usually changes from 0.01 to 0.18 .

The produced solar array output energy is calculated by below expression:

$E_{p V}=P_{o u t}\left(E_{x}\right) \cdot($ solar window $) \cdot($ Total Day $)$ 
Where $E_{P V}$ is the produced output energy by the solar array in $(K w)$, Solar Window is total time hours that the sun hit the PV array at an average hourly solar radiation, Total Day is used to alternate calculation of daily to monthly or yearly, and $P_{\text {out }}\left(E_{x}\right)$ is the PV array output power at an mean value of hourly solar radiation $\left(E_{x}\right)$. Figure 7 is demonstrated I-V and P-V characteristics of solar array. Also the specification of the selected solar panel is presented at Table 1.

Table 1. PV array parameters

\begin{tabular}{c|c|c|c|c|c|c}
\hline $\begin{array}{c}\text { PV } \\
\text { array } \\
\text { Type }\end{array}$ & $\begin{array}{c}\text { Nominal } \\
\text { Voltage } \\
(\mathbf{V})\end{array}$ & $\begin{array}{c}\text { Nominal } \\
\text { Current } \\
(\mathbf{A})\end{array}$ & $\begin{array}{c}\text { Short-circuit } \\
\text { current } \\
\text { at } \mathbf{S T C}(\mathbf{A}) \\
\left(\mathbf{I}_{\mathbf{S C}}\right)\end{array}$ & $\begin{array}{c}\text { Open-circuit } \\
\text { voltage } \\
\text { at } \mathbf{S T C}(\mathbf{V}) \\
\left(\mathbf{V}_{\mathbf{O C}}\right)\end{array}$ & $\begin{array}{c}\text { Temperature } \\
\text { coefficient of } \\
\mathbf{I}_{\mathbf{S C}}\left(\% /{ }^{\circ} \mathbf{C}\right) \\
\left(\mathbf{T}_{\mathbf{C i}}\right)\end{array}$ & $\begin{array}{c}\text { Temperature } \\
\text { coefficient of } \\
\mathbf{V}_{\mathbf{O C}}\left(\% /{ }^{\circ} \mathbf{C}\right) \\
\left(\mathbf{T}_{\mathbf{C v}}\right)\end{array}$ \\
\hline $\mathrm{KC} 200$ & 26.3 & 7.6 & 8.2 & 32.9 & 0.003 & -0.123 \\
\hline
\end{tabular}
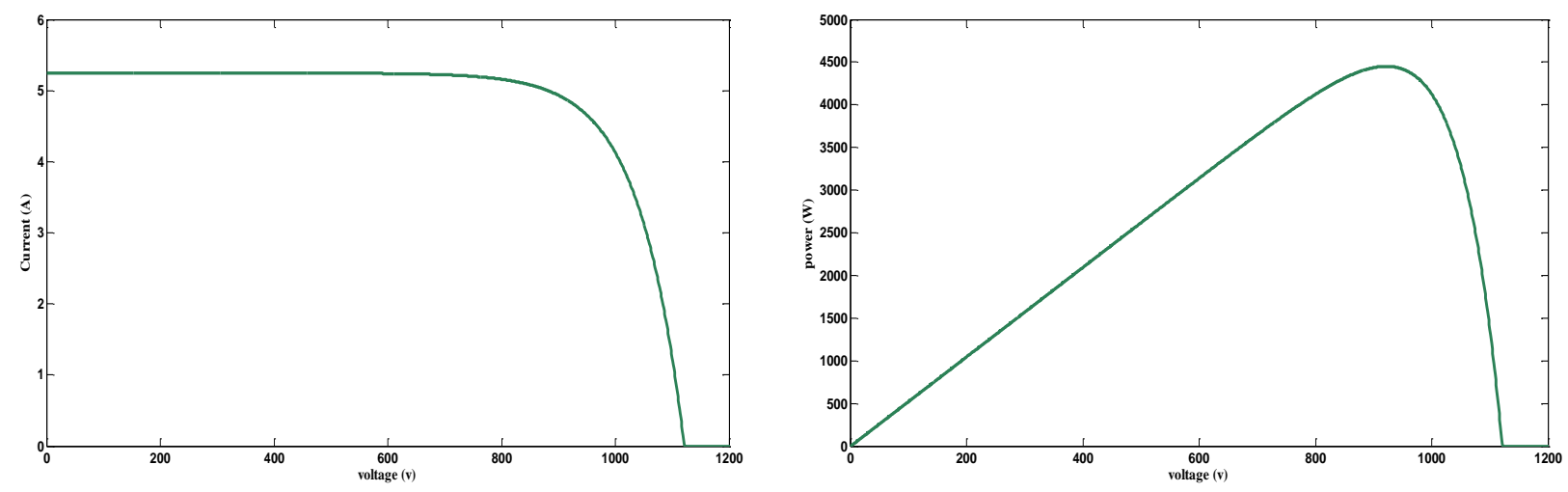

Figure 7. I-V and P-V characteristics of solar array

\subsection{Operation of BT}

A storage system is an essential component in renewable energy systems because of the probability and unpredictable nature of renewable sources. BT could supply requirement stand-alone system power at the time that the sources are unable to provide the demand. Very different model is used to model the BT in the literatures. State of charge (SOC) is a mostly usual model which is used in this paper [20]. Some parameters that affect the BT behaviors are considered in BT model, such as the charging current rate, the charging efficiency, the self-discharge rate and also the BT capacity.

Capacity of the BT depends on temperature. Capacity of the BT changes by the coefficient temperature $\delta_{C}$ :

$C_{b a t}^{\prime}=C_{b a t^{\prime}}^{\prime \prime}\left(1+\delta_{c} \cdot\left(T_{b a t}-298.15\right)\right)$ 
Where $C_{b a t}^{\prime}(A h)$ is the changed BT capacity by the temperature, $C_{b a t}^{\prime \prime}(A h)$ the nominal capacity which is reported by manufactures datasheet, $T_{b a t}$ is the BT temperature in $(\mathrm{K})$ and $\delta_{c}$ is temperature coefficient and [21] suggested $0.6 \%$ per degree if the manufactures do not report in datasheets.

The BT current rate at time $\mathrm{t}$ is described by:

$I_{b a t}(t)=\frac{p_{P V}(t)+p_{W T}(t)-p_{A C \text { load }}(t) / \text { ninvertar }-p_{D C \text { load }}\left(t^{\prime}\right.}{V_{\text {bat }}(t)}$

Where $\eta_{\text {inverter }}$ the inverter coefficient is $92 \%, P_{P V}$ the output PV power, $P_{W T}$ the output WT power, $P_{A C l o a d}$ the AC load power, $P_{D C \text { load }}$ the DC load power and $V_{\text {bat }}$ is the BT voltage. With considering these factors, SOC could be calculated as below:

$\operatorname{SOC}(t+1)=\operatorname{SOC}(t) \cdot\left(1-\frac{\sigma \Delta t}{24}\right)+\frac{I_{b a t}(t) \Delta t \cdot m_{b a t}}{C_{b a t}^{t}}$

Where $\sigma$ is the self-discharge rate and proposed value of $0.2 \%$ per day is recommended, $\eta_{b a t}$ is the BT efficiency, which is $90 \%$ for charging and $100 \%$ for discharging [22].

SOC is utilized as a decision parameter for the control of BT charging. The overcharge may happen when higher power is produced by the renewable power sources, or when the demand is low. In this state when the BT SOC arrives the maximum value, $S O C_{\max }=1$, the control system stops the charging. Likewise, if the charging state reaches to the minimum value, $S O C_{\min }=1-D O D$, the control system interrupted the discharging process. DOD in this research is considered as $60 \%$. This is significant to inhibit batteries decreasing lifespan or even be ruined. The selected BT characteristics are demonstrated in Table 2.

Table 2. BT characteristics

\begin{tabular}{c|c|c|c|c|c}
\hline Nominal voltage(v) & Rated capacity (Ah) & Width $(\mathbf{m})$ & $\begin{array}{c}\text { Length } \\
(\mathbf{m})\end{array}$ & Height $(\mathbf{m})$ & Weight $(\mathbf{K g})$ \\
\hline 22.40 & 0.206 & 0.258 & 0.166 & 60 & 12 \\
\hline
\end{tabular}

\section{Economical Analysis}

The optimal sizing of a hybrid renewable energy system according to economy supply the optimum balance between the demand and system cost. Unit Cost of Electric Energy (UCEE) is an economic approach based on annualized cost of the system (ACS) which is given the best cost of the possible hybrid system [23]. 
The ACS is consisted of an annualized capital cost $\left(C_{\text {acap }}\right)$, annualized replacement cost $\left(C_{\text {arep }}\right)$ and maintenance cost $\left(C_{\text {amain }}\right)$ [23] and can be computed by

$A C S=C_{a c a p}+C_{a r a p}+C_{a m i n}$

\subsection{Annualized Capital Cost $C_{a c a p}$}

Where the annualized capital cost for each the hybrid system components is expressed as

$C_{a c a p}=C_{c a p}, \operatorname{CRF}\left(i, Y_{p r o j}\right)$

Where $C_{c a p}$ illustrate the capital cost of each component in (\$), $Y_{\text {proj }}$ the economic lifespan of the entire project in (year) and $C R F$ is the capacity recovery factor which is presented by [23]:

$\operatorname{CRF}(i, n)=\frac{i(1+i)^{n}}{(1+i)^{n-1}}$

Where $n$ the component lifetime in (year), $i$ the annual interest rate related to the nominal interest rate. Here we are used given below statement to obtain parameter $i$ :

$i=\frac{i_{\operatorname{loon}}-f}{1+f}$

In equation (15) $i_{\text {loan }}$ is the rat of loan and $f$ is the annual inflation rate.

\subsection{Operation and Maintenance Cost, $C_{a m a i n}$}

The other parameter of ACS is operational and maintenance. This parameter is utilized to calculate cost of maintenance and operational of each components in hybrid renewable system. The mathematic equation is demonstrated effective terms in calculating $C_{\text {amain }}$ :

$C_{a \operatorname{main}}(n)=C_{a \operatorname{main}}(1) \cdot(1+f)^{n}$ 
Where $C_{\text {main }}(\$)$ denotes the operation and maintenance cost at nth year.

\subsection{Annualized Replacement Capital Cost, $C_{a r e p}$}

The annualized replacement capital cost, $C_{\text {arep }}$ in (\$), of each component of ACS in Eq. (17) is represented as:

$C_{\text {arap }}=C_{r \theta p} \cdot S F F\left(i, Y_{r \theta p}\right)$

Where $C_{\text {rep }}$ is replacement cost abbreviation of each component in (\$), $Y_{r e p}$ is lifespan of each components in (year), $i$ is interest rate and $S F F$ the sinking fund factor. SFF is considered as below:

$\operatorname{SFF}\left(i, Y_{\text {rap }}\right)=\frac{i}{(1+i)^{Y_{\text {rEp }}-1}}$

Finally, UCEE is calculated in accordance to ACS as:

$U C E E=\frac{A C S}{A T E D}$

Where ATED stands the annual total energy demand in (kWh). In accordance to the economic method, it should be noted that the optimal configuration will be reached by the lowest UCEE. The costs and lifespans of the components are demonstrated in Table 3.

\section{Reliability of Renewable Hybrid System}

The first step in the optimization sizing problem is modeling of components. In previous sections were proposed PV array, WT and BT models. The second step includes sizing procedure of a stand-alone microgrid system according to economic aspects. The third step of stand-alone microgrid optimal sizing system is the loss of power supply probability (LPSP) concepts to conform the reliability of the proposed system.

LPSP indicates the probability of the renewable system when the power sources cannot supply the demand [9]. LPSP of 0 indicates load will be completely satisfied by the power sources; and a LPSP of 1 indicates load will not be satisfied any way.

Table 3. The costs and lifespans of the system components 


\begin{tabular}{|c|c|c|c|c|c|c|}
\hline Components & $\begin{array}{c}\text { Initial } \\
\text { capital cost }\end{array}$ & $\begin{array}{c}\text { Maintenance } \\
\text { cost } \\
\text { in the first } \\
\text { year }\end{array}$ & $\begin{array}{c}\text { Replacement } \\
\text { cost }\end{array}$ & $\begin{array}{c}\text { lifespan } \\
\text { (year) }\end{array}$ & $\begin{array}{l}\text { interest } \\
\text { rate }\end{array}$ & $\begin{array}{c}\text { Inflation } \\
\text { Rate }\end{array}$ \\
\hline PV & $\begin{array}{c}800 \\
(\mathrm{US} \$ / \mathrm{kW})\end{array}$ & $70(\mathrm{US} \$ / \mathrm{kW})$ & Null & 20 & $5 \%$ & $2 \%$ \\
\hline WT & $\begin{array}{c}600 \\
(\mathrm{US} \$ / \mathrm{kW})\end{array}$ & $100(\mathrm{US} \$ / \mathrm{kW})$ & Null & 20 & $5 \%$ & $2 \%$ \\
\hline WT tower & $\begin{array}{c}806.86 \\
(\mathrm{US} \$ / \mathrm{m})\end{array}$ & $6.5(\mathrm{US} \$ / \mathrm{m})$ & Null & 20 & $5 \%$ & $2 \%$ \\
\hline $\mathrm{BT}$ & $\begin{array}{c}125 \\
\text { (US\$/kAh) }\end{array}$ & 30 (US\$/kAh) & $\begin{array}{c}124.12 \\
\text { (US\$/kAh) }\end{array}$ & 5 & $5 \%$ & $2 \%$ \\
\hline
\end{tabular}

As it mentioned, LPSP is the probability of power failure time of the system and calculated as

$L P S P=\frac{\sum_{t=0}^{f} T \operatorname{tm\theta }\left(P_{\text {available }}(t)<P_{-} n \theta \theta d \theta d(t)\right)}{\tau}$

Where $T$ is the considered simulation number of hours, $P_{\text {needed }}$ is the sum of the demands at time $t$ expressed as:

$P_{\text {neded }}(t)=\frac{P_{\text {AC load }}(t)}{n_{\text {inverter }}(t)}+P_{D C \text { load }}(t)$

The power available is expressed by

$P_{\text {available }}(t)=P_{p V}+P_{W T}+C \cdot V_{b a t} \cdot \operatorname{Min}\left[I_{b a t \max }=\frac{0.2 C_{\mathrm{bat}}^{t}}{\Delta t}, \frac{C_{\mathrm{bat}}^{t} \cdot\left(\operatorname{soC}(t)-\operatorname{soc} C_{\min }\right)}{\Delta t}\right]$

Where $C$ is 0 for charging BT state and 1 for BT discharging state.

\section{Load Demand Profile}

A domestic load data is used as a case study. The hourly off-grid load profile in Marvdasht area is shown in Figure 8. Hourly load demand for 1 year in Marvdasht.

\section{System Optimization Model}




\subsection{Flowchart and Optimization Procedures}

The BT is used to store the energy surplus and to supply the load demand in case of low wind speed and/or irradiation conditions. Therefore, charging and discharging state of BT should be specified. The flowchart of management procedure is expressed in Figure 11.

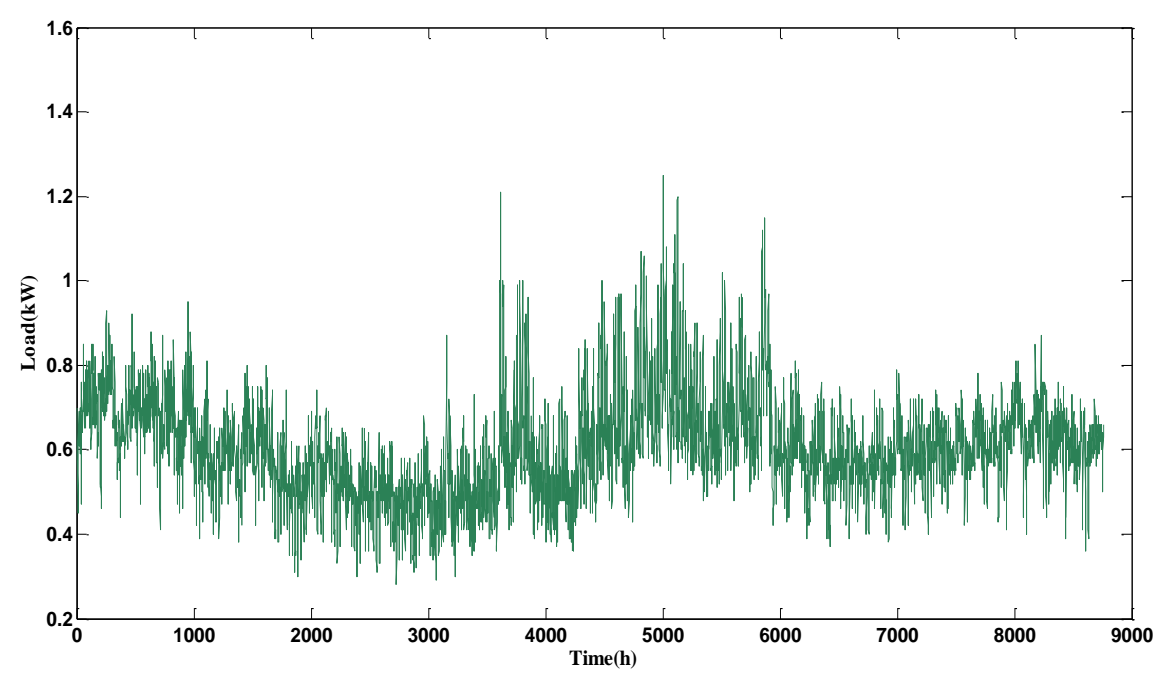

Figure 8. Hourly load demand for 1 year in Marvdasht.

The presented operation flowchart is as follows:

1) If the power demand is less than the total output power of the WTs and PV arrays, $\left(P_{L}<P_{w t}+P_{P V}\right)$, the charging process is happened. The excess energy is stored in BT, and new SOC will be calculated. The higher limit of the SOC is $\mathrm{SOC}_{\max }$. If the battery SOC meets the $\mathrm{SOC}_{\max }$ then the surplus power will dump and the SOC value $\mathrm{SOC}_{\max }$. In this situation the LPSP is equal to zero, because the sources could completely supply the demand. The UCEE, number of PV panels, and number of WT will be calculated.

2) If the power demand is greater than the total power output of the WTs and PV arrays, $\left(P_{L}>P_{w t}+P_{P V}\right)$, the discharging process will happen. The power deficiency can be supplied by the BT. New SOC will be calculated. It will be also checked not to getting out of the lower limit, $\mathrm{SOC}_{\min }$. In this condition, the LPSP must be taken account by equation (20), because the sources could not supply the demand in all hours. The UCEE, the number of PV arrays, WTs, and BTs will be estimated.

\subsection{Objective Function and Constrains Defining}

The main point of this paper is obtaining the best configuration of the hybrid renewable system of $\mathrm{PV} / \mathrm{WT} / \mathrm{BT}$ for the stand-alone microgrid area. To aim this goal UCEE is used as an objective function. 
By minimizing UCEE could achieve to an adequate configuration with the lowest costs. So the objective function of the proposed hybrid renewable system can be expressed as:

Objective: $\min _{n}\left(n_{p V} \times U C E E_{p V}+n_{w t} \times U C E E_{w t}+n_{b a t t} \times U C E E_{b a t t}\right)$

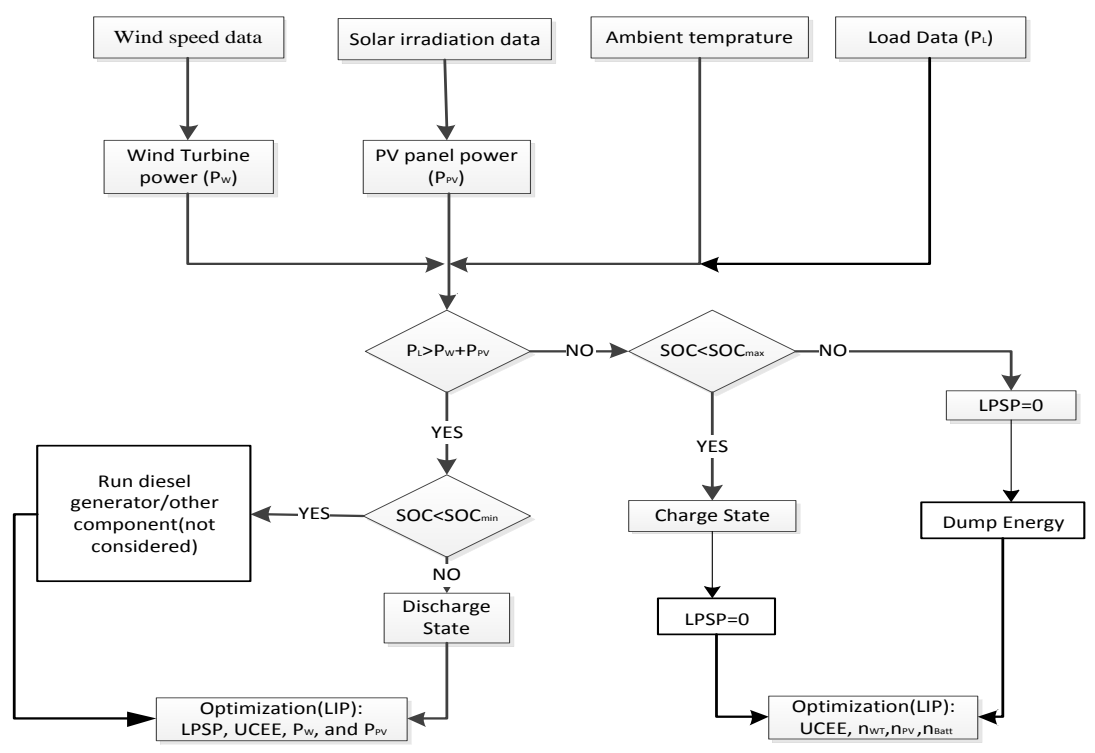

Figure 9. Optimization and charging/discharging of the BT procedure

In equation (23), $n_{i}$ is the problem variables which is composed of number of PV array, number of WT and number of batteries. LPSP is employed to evaluate the best reliability criterion. To reach the 3 day storing for BT, value of 3\% is proposed for the desired LPSP. In addition the BT state of charge must be in a safe range to avoid becomes spoiled, overcharging and over discharging. So the problem subjects are presented as:

Subject: $0<$ LPSP $<0.03$

$$
S O C_{\min }<S O C<S O C_{\max }
$$

In accordance to equations (23) and (24), it is obvious that optimization problem is linear. In other hand the variables must be integer and the constrain of the optimization sizing problem is

$n_{p V}, n_{w t}, n_{b a t t} \in \mathbb{Z}$

By attention on the objective function, subject and other constrains it is clear the best classical optimization way, is linear integer programing (LIP). Branch and cut [[24] is a usual method optimization 
for solving linear problems, where some or all the values are integer [25]. Branch and cut includes a branch and bound algorithm and utilized cutting planes to reach the integer linear programming. The proposed LIP program related on the flowchart that is illustrated in Figure 9 is coded in Matlab® environment.

\section{Results}

The proposed methodology has been used to achieve the proper size of off-grid power system, to supply the load demand of a remote area by using of branch and cut based on linear integer programing (LIP). The typical meteorological of one year hourly data collected for solar radiation, temperature and wind speed. The location of Marvdasht, Fars, Iran (Latitude: $29^{\circ} 50^{\prime} \mathrm{N}$, Longitude: 52 $40^{\prime} \mathrm{E}$ ) is chosen for case study. Results displayed as an optimal Pareto front. Each solution of the best Pareto front was achieved by a combination of hybrid systems in some manner to reach higher reliability . The best configurations among the results are shown in Table 4. The proper size of components is calculated according to the operation procedure which described before.

The lowest Unit cost of electricity energy (UCEE) achieved in related on the candidate number 5 but the lowest LPSP is given by choice 3. The Loss of power supply probability (LPSP) for one month is demonstrated in Figure 10. LPSP of one month, LPSP is completely well controlled to be less than $3 \%$ as desired LPSP.

Table 4. optimal solutions of components

\begin{tabular}{c|c|c|c|c}
\hline PV number & WT number & BT number & $\begin{array}{c}\text { UCEE } \\
\mathbf{( \$ / k W )}\end{array}$ & LPSP\% \\
\hline 2 & 2 & 1 & 257.6142 & 1.24 \\
1 & 1 & 4 & 191.1375 & 2.40 \\
2 & 1 & 2 & 211.8478 & 0.00 \\
2 & 2 & 2 & 196.7711 & 2.85 \\
3 & 2 & 1 & 187.5020 & 0.53 \\
\hline
\end{tabular}

The battery SOC is shown in Figure 11. SOC of one month for one month. It is noteworthy that the battery SOC is in the $\mathrm{SOC}_{\max }$ and the $\mathrm{SOC}_{\min }$ range, so the longest lifespan of the battery is ensured by the proposed management strategy.

The relation between LPSP and UCEE is shown in Figure 12. With increasing the LPSP the value of the UCEE is decreased and vice versa by decreasing the value of the LPSP the UCEE is increasing. The Branch and cut method is a suitable method to reach the best size. It is needed lower time in comparison of the evolutionary methods to reach the results and it guarantees that the obtain results is really the optimal solution. 


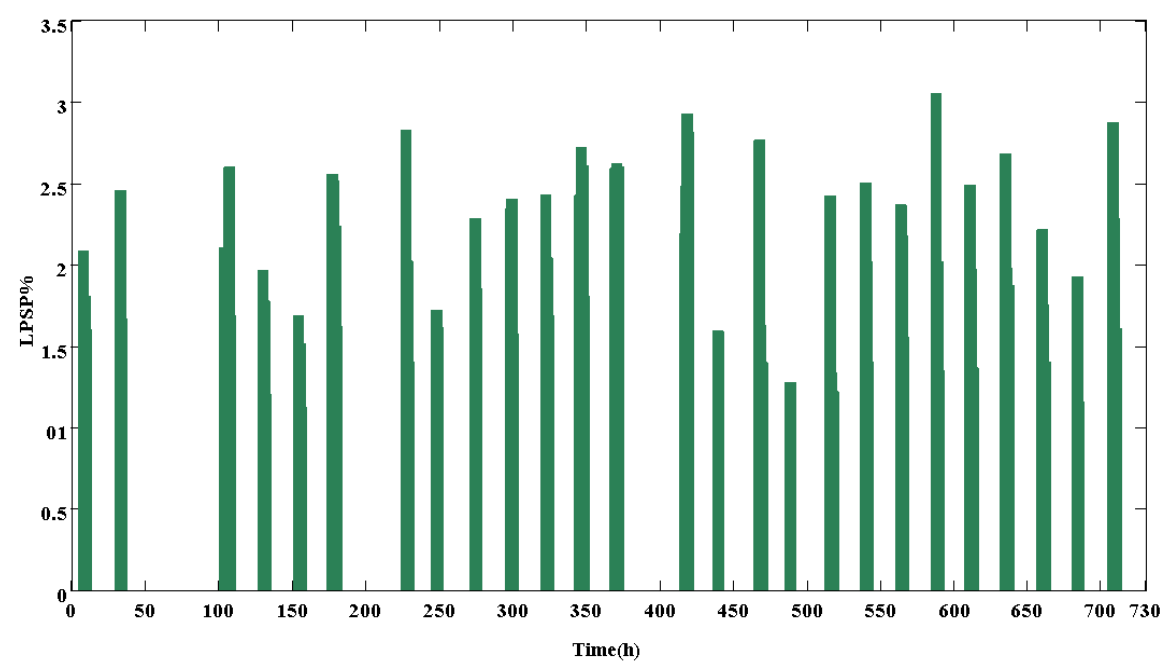

Figure 10. LPSP of one month

\section{Conclusion}

A methodology of economical optimal sizing of a stand-alone hybrid wind/PV power systems using the Branch and cut method is proposed in this paper.

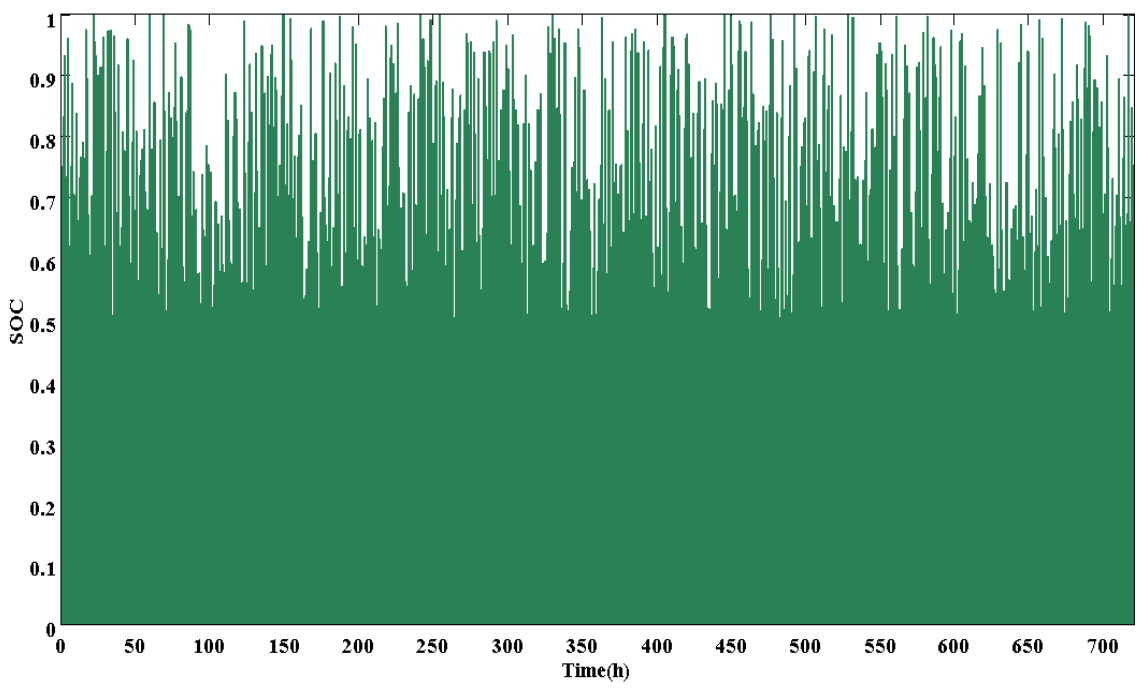

Figure 11. SOC of one month

The proposed hybrid system is composed of PV and WT, as the power sources, and BT, as storage system to sore excess power. The optimal size of a renewable hybrid system for Marvdasht as a case study is investigated. The objective functions are considered to minimize the cost of project and also 
maximize the power reliability of the system. The unit cost of electricity energy (UCEE) used as the objective function for economical calculations and state of charge of BT (SOC) and loss of power supply probability (LPSP) employed as constraints. It is taking 3\% value of LPSP to reach 3 days storage. A management strategy for BT is proposed protects it against destruction. By applying a Branch and cut method to the proposed linear integer programing (LIP) problem, the proper size of components which could meet the load demand in the lowest cost is obtained. According the results the best size of components are, 3, 2 and 1 for PV, WT and BT respectively. The UCEE of this candidate is 187.5020 $(\$ / \mathrm{kW})$ and the LPSP is $0.53 \%$, but if needed the zero for LPSP the best configuration is ,2,1, 2 and 211.8478 for PV, WT, BT and UCEE respectively.

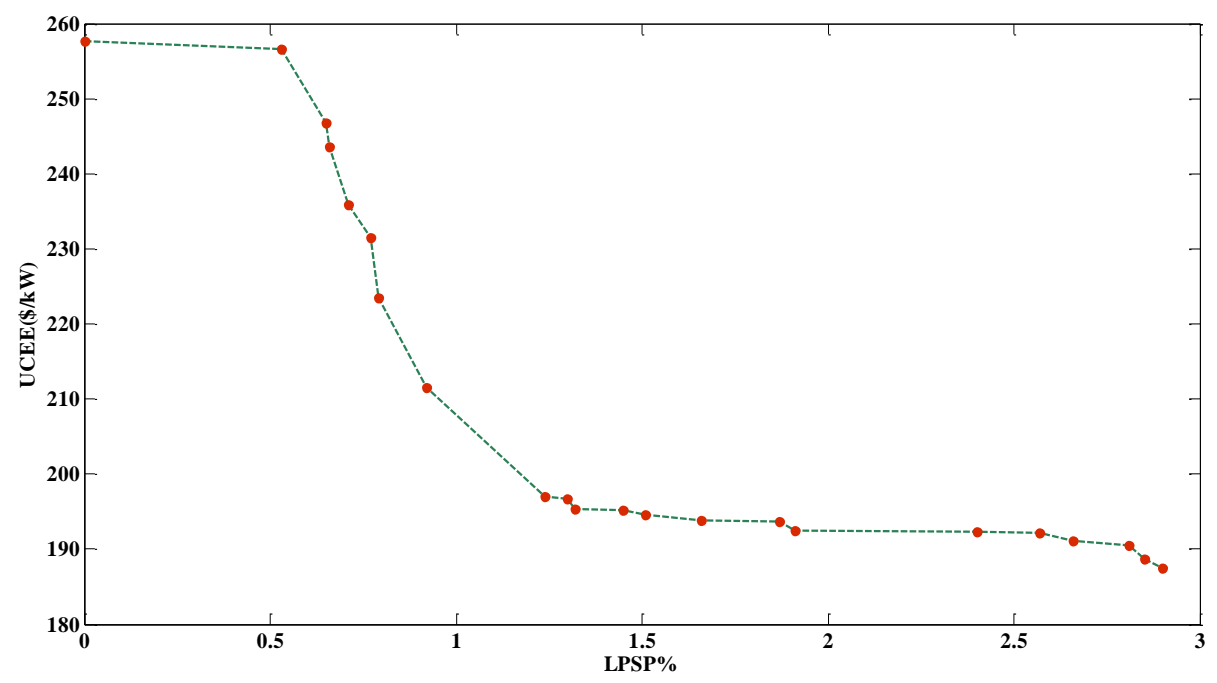

Figure 12. UCEE and LPSP

\section{References}

[1] Vafaei, M., Optimally-Sized Design of a Wind/Diesel/Fuel Cell Hybrid System for Remote Community, Master of Applied Science Electrical and Computer Engineering University of Waterloo, 2011.

[2] Hongxing Yang, Lin Lu and Wei Zhou., A novel optimization sizing model for hybrid solar-wind power generation system, Solar Energy 81(1), 76-84, 2007.

[3] Claudia Valéria Távora Cabral, Delly Oliveira Filho, Antônia Sônia Alves C. Diniz, José Helvecio Martins, Olga Moraes Toledo and Lauro de Vilhena B. Machado Neto., A stochastic method for standalone photovoltaic system sizing, Solar Energy 84(9), 1628-1636, 2010.

[4] A.D. Bagul, Z.M. Salameh and B. Borowy, Sizing of a stand-alone hybrid wind-photovoltaic system using a three-event probability density approximation, Solar Energy 56(4), 323-335, 1996. 
[5] Abouzahr, I. and Ramakumar R., Loss of power supply probability of stand-alone photovoltaic systems: a closed form solution approach, Energy Conversion, IEEE Transactions on Energy Conversion 6, 1-11, 1991.

[6] Li, Jing, Wei Wei, and Ji Xiang, A simple sizing algorithm for stand-alone PV/wind/battery hybrid microgrids, Energies 5(12), 5307-5323, 1991.

[7] S. Diaf, M. Belhamel, M. Haddadi and A. Louche, Technical and economic assessment of hybrid photovoltaic/wind system with battery storage in Corsica island, Energy Policy 36(2), 743-754, 2008.

[8] Tomas Markvart, Sizing of hybrid PV-wind energy systems, Sol Energy 59(4), 277-81, 1996.

[9] Yang HX, Burnett $\mathbf{J}$ and $\mathrm{Lu} \mathrm{L}$, Weather data and probability analysis of hybrid photovoltaic-wind power generation systems in Hong Kong, Renew Energy 28(11), 1813-24, 2003.

[10] S. Ashok, Optimized model for community-based hybrid energy system, Renewable Energy 32(7), 1155-1164, 2007.

[11] Javed Dhillon, Multi objective Optimization of Power Dispatch Problem Using NSGA-II, Master of Engineering Power Systems \& Electric Drives, Thapar University, Patiala, 2009.

[12] Eftichios Koutroulis, Dionissia Kolokotsa, Antonis Potirakis, and Kostas Kalaitzakis, Methodology for optimal sizing of stand-alone photovoltaic/wind-generator systems using genetic algorithms, Solar Energy, 1072-1088, 2006.

[13] Jahromi Mohammad Ali Yazdanpanah, Farahat, Said and Barakati, Seyed Masoud, Optimal size and cost analysis of stand-alone hybrid wind/photovoltaic power-generation systems, Civil Engineering and Environmental Systems, 1-21, 2013.

[14] Bahman Bahmani-Firouzi and Rasoul Azizipanah-Abarghooee, Optimal sizing of battery energy storage for micro-grid operation management using a new improved bat algorithm, International Journal of Electrical Power \& Energy Systems 56, 42-54, 1013.

[15] Motaz Amer, A. Namaane and N.K. M'Sirdi, Optimization of Hybrid Renewable Energy Systems (HRES) Using PSO for Cost Reduction, Energy Procedia 42, 318-327, 2013.

[16] Masoud Sharafi and Tarek Y. ELMekkawy, Multi-objective optimal design of hybrid renewable energy systems using PSO-simulation based approach, Renewable Energy, 68, 67-79, 2014.

[17] Adrian Ilinca, Ed McCarthy, Jean-Louis Chaumel and Jean-Louis Rétiveau, Wind potential assessment of Quebec Province, Renewable Energy 28(12), 1881-1897, 2003.

[18] Yazdanpanah-Jahromi, M. A., Barakati, S.-M. and Farahat, S, An efficient sizing method with suitable energy management strategy for hybrid renewable energy systems, International Transactions on Electrical Energy Systems, 2013. 
[19] Ortiz Rivera EI, Modeling and analysis of solar distributed generation, Ph.D. thesis, Department of Electrical and Computer Engineering, Michigan State University, 2006.

[20] Piller, S., Perrin, M. and Jossen, Methods for state-of-charge determination and their applications, Power Sources 96, 113-120, 2001.

[21] Berndt, D, Maintenance-free Batteries, John Wiley \& Sons, England, 1994.

[22] Guasch, D. and Silvestre, S, Dynamic battery model for photovoltaic applications, Progress in Photovoltaics: Research and Applications, 11, 193-206, 2003.

[23] Yang H, Zhou W, Lu L and Fang Z, Optimal sizing method for stand-alone hybrid solar-wind system with LPSP technology by using genetic algorithm, Solar Energy, 67, 82-354, 2008.

[24] Padberg, M. and Rinaldi, G, A Branch-and-Cut Algorithm for the Resolution of Large-Scale Symmetric Traveling Salesman Problems, Siam Review, 60-100, 1991.

[25] John E. and Mitchell, Branch-and-Cut Algorithms for Combinatorial Optimization Problems, Handbook of Applied Optimization, 65-77, 2002. 